\title{
How much and why are we willing to pay for energy-efficient homes? A stated preferences analysis in Barcelona
}

\author{
Carlos Marmolejo-Duarte ${ }^{1}$ | Alejandra García-Hooghuis ${ }^{2}$ | Anna García Masià ${ }^{3}$
}

Received: 2019-06-06 | in its last version: 2020-02-11

Abstract

In the literature, the empirical evidence on the green premium for energy-efficient homes does not provide the reasons that produce such price increment. This paper, using stated preferences surveys, explores whether households in Barcelona are willing to pay (WTP) for an improvement in the ranking coming from Energy Performance Certificates (EPC) and the reasons explaining its variance. The results suggest that, in general, people are unaware of the EPC scheme, and tend to confound energy performance of homes with the overall architectonic quality. Such limitations reduce the WTP for efficient homes, while other perceptions such as comfort and an improved health condition associated with energy performance appear as positively correlated. Furthermore, the stratified analysis indicates the existence of divergent sensibilities associated with socioeconomic conditions. On the whole, it poses important challenges for the design of public policies aimed at fostering the diffusion of energy-efficient homes. The findings of this paper imply important challenges for the communication of the EPC policy in Spain, not only because society is not monolithic, having divergent motivations when bidding for efficient housing, but also because superficial information seems to be inefficient in creating awareness on the implication of the energy performance of buildings.

Keywords: Contingent valuation; real estate valuation; energy efficiency; energy performance certificate

Citation

Marmolejo, C. et al. (2020). How much and why are we willing to pay for energy-efficient homes? A stated preferences analysis in Barcelona, ACE: Architecture, City and Environment, 14(42), 9215. DOI: http://dx.doi.org/10.5821/ace.14.42.9215

\footnotetext{
1 Ph.D. Architect, Associate professor, Department of Architectural Technology, Technical University of Catalonia (ORCID: 0000-0001-7051-7337, Researcher ID: D-9162-2016, Scopus Author ID: $\underline{35178192000}),{ }^{2}$ M. Sc. Architect, Senior Digital Solutions Consultant, Minisait by INDRA ${ }^{3}$ Sociologist, Ph.D., Civic Participation Technique, Deputation of Barcelona. Contact: carlos.marmolejo@upc.edu
} 


\section{Introduction}

In order to address $\mathrm{CO} 2$ emissions and energy dependency the EC designed the Energy Performance of Buildings Directive (EPBD 2002/91/EC), recast in 2010 and 2018. The national transpositions of such Directive oblige to exhibit "energy labels" derived from Energy Performance Certificates (EPC) when properties are transacted. The aim of such labels is to bring energy information transparency to the real estate market using a simple ranking (e.g. being " $A$ " the most efficient building and " $G$ " the most inefficient) and providing information on energy consumption and CO2 emissions. It can be expected that better-ranked properties exhibit a green premium due to energy savings and environmental conservation. Eventually, increased market prices for efficient buildings may offset over costs associated with efficient construction fostering the development of efficient buildings (MarmolejoDuarte \& Chen, 2019).

While a number of studies, revised in section 2, have shown the magnitude of the aforementioned premium in the residential market; others have found that such a premium is, in fact, a proxy of other architectural and building quality aspects, rather than the energy efficiency itself, rendering no conclusive evidence. Furthermore, none of these studies provide actual motivations of households to deliver such extra payment, if any. This latter information is of paramount interest in promoting the diffusion of efficient buildings and the EPC scheme itself.

This paper, using a stated preferences approach, explores: 1) whether households in Barcelona are willing to pay (WTP) for EPC efficient homes, and 2) the motivations declared to do it. The Spanish case is interesting in three respects, since: i) the EPBD was transposed overnight (RD 235/2013) and due to public budget constraints the diffusion was extremely limited; ii) owing to mild winters housing energy demand is less important in relation to continental and northern countries in Europe; and, iii) previous research has pointed out that people do not completely understand the technical units of energy consumption and emissions of energy labels. These reasons, on the one hand, pose in question whether the EPC scheme is producing the expected outcomes in promoting energy-efficient housing in Spain. On the other hand, they suggest the necessity to explore the impact on WTP produced by the technical units used to communicate both energy consumption and CO2 emissions, as well as the information related to the architectonic attributes that impact the energy performance of homes. For these reasons, three versions of the survey used to extract the WTP for efficient homes were used as explained in the methodological section.

The remainder of the paper is organized as follows: first a review of the previous research on EPC rankings and real estate prices both in Europe and Spain is offered; second the case study, data, and methodology is explained; as a third part the results are discussed, and in the concluding section an overview of the work and its implications for the building industry are given.

\section{Brief literature review}

Despite the relatively recent transposition of 2010 EPBD, there is growing empirical evidence on the impact of EPC ranking on residential prices. Table 1 details a selection of studies indicating the source of information, scale in which EPC ranking has been analysed and their main findings. All of the reviewed studies implemented a hedonic analysis. Such an approach assumes that the transaction

ACE, 14 (1.2) CC BY-ND 3.0 ES | UPC Barcelona, España | How much and why are we willing to pay for energyefficient homes? A stated preferences analysis in Barcelona. DOI: http://dx.doi.org/10.5821/ace.14.42.9215 
price of homes can be split in marginal prices coming from locative and structural attributes, including EPC ranking. Most of them use transaction or listing prices and consider EPC ranking to be understood as a categorical scale of energy efficiency. As can be noted, the marginal price for energy efficiency exhibits a significant variation across Europe, and even in different cities of the same country. Such fact can be explained by divergent climates (and consequently heating and cooling energy demands), construction materials, techniques and codes, energy and housing prices, and perhaps, cultural concerns related to environmental conservation. However, the impact of EPC rankings is not always positive. An example of such a situation is the work of Bio Intelligence Service et al. (2013) who found the semi-elasticity for each step of the EPC ladder to be $-4 \%$. As these authors explain, poor control on concomitant attributes (e.g. quality and location) on statistical models can bias the regression coefficients. In the same line, Marmolejo (2016) found, in Barcelona, that EPC rankings become statistically significant only when micro-locative attributes are controlled. According to this author, this finding suggests that the hedonic agenda of EPC ranking has spatial implications. In further work (Marmolejo-Duarte \& Chen, 2019a) such implications are studied by splitting the residential market into segments. The results of this latter study found that EPC ranking, in Barcelona, has a null impact of prices in the case of brand-new apartments boasting the best architectonic amenities. Conversely, in the segment of post-war apartments, EPC rankings play an incorrect role in price differentiation: in absence of structural amenities EPC rankings proxies for home quality. Marmolejo et al. (2020) have arrived at similar conclusions using a geographically weighted hedonic approach. The null impact of EPC rankings on prices is not a novelty in Europe. Fregonara \& Rolando (2017) found, in Turin, after controlling other architectural and construction quality attributes the EPC semi-elasticity to be zero. In this same line, Olaussen et al. (2017) performed a quasi-natural experiment using a repeated sales approach in Norway. Their results suggest that even before the EPC scheme came into force nonlabeled "efficient homes" depicted a market premium, concluding that EPC labels are not responsible for such premium, but perhaps omitted quality variables which in turn are correlated with efficient EPC rankings. To the same conclusions arrive the study of Olaussen et al. (2019, p. 1) comparing the actual value of energy savings with the market premium for energy-efficient homes in Oslo: "we conclude that not only the energy label, but also the energy performance of dwellings in general, has little to no effect on transaction prices".

Evidence coming from opinion-based research is also supportive of a null role of EPC raking on price formation. Murphy (2014) conducted a survey in the Netherlands in order to identify the impact of EPC information on price negotiation in the context of home purchasing. Her results suggest that "a higher EPC fails to have a direct influence during negotiation and decision making". Parkinson et al. (2013) have found, surveying commercial office occupants in the UK, no correlation between EPC ratings and rental values, their findings suggest that facilities' aesthetic is the main driver of rents.

Compatible evidence can be found in the study of Pascual et al. (2017) based on surveys applied to real estate agents in eight European countries. According to their results, EPC ratings exert a negligible impact on housing prices. This conclusion is especially valid in the case of Spain where only $15 \%$ of the surveyed agents confirmed the existence of a premium for efficient flats. In any case, while the influence of EPC ranking on prices is inconclusive, none of the reviewed studies explore the reasons motivating the possible extra-WTP for high EPC-ranked homes.

ACE, 14 (12) CC BY-ND 3.0 ES | UPC Barcelona, España | How much and why are we willing to pay for energyefficient homes? A stated preferences analysis in Barcelona. DOI: http://dx.doi.org/10.5821/ace.14.42.9215 
Table 1. Selected studies researching the hedonic agenda of EPC rankings

\begin{tabular}{|c|c|c|c|c|c|c|c|}
\hline \multirow[t]{2}{*}{ Study cases } & \multirow[t]{2}{*}{ Market } & \multirow[t]{2}{*}{$\begin{array}{c}\text { Scale type as } \\
\text { interpreted by EPC } \\
\text { ratings }\end{array}$} & \multicolumn{2}{|c|}{$\begin{array}{c}\text { Marginal impact of EPCs } \\
\text { on }\end{array}$} & \multirow[t]{2}{*}{$\begin{array}{l}\text { From energy } \\
\text { rating } X \text { to } Y \\
(X / Y)\end{array}$} & \multirow[t]{2}{*}{$\begin{array}{l}\text { Type of } \\
\text { prices }\end{array}$} & \multirow[t]{2}{*}{ Authorship } \\
\hline & & & Sale & Rent & & & \\
\hline \multirow{6}{*}{ Netherlands } & \multirow{6}{*}{ Residential } & \multirow{6}{*}{ Categorical } & $10.00 \%$ & & $A / D$ & \multirow{6}{*}{ Closing } & \multirow{6}{*}{$\begin{array}{l}\text { Brounen \& } \\
\text { Kok (2011) }\end{array}$} \\
\hline & & & $5.50 \%$ & & $\mathrm{~B} / \mathrm{D}$ & & \\
\hline & & & $2.00 \%$ & & $C / D$ & & \\
\hline & & & $-0.50 \%$ & & $E / D$ & & \\
\hline & & & $-2,50 \%$ & & F/D & & \\
\hline & & & $-5.00 \%$ & & $\mathrm{G} / \mathrm{D}$ & & \\
\hline \multirow{4}{*}{ Ireland } & \multirow{4}{*}{ Residential } & \multirow{4}{*}{ Categorical } & $9.30 \%$ & $1.80 \%$ & $A / D$ & \multirow{4}{*}{ Listing } & \multirow{4}{*}{$\begin{array}{l}\text { Hyland et al. } \\
\text { (2013) }\end{array}$} \\
\hline & & & $5.50 \%$ & $3.90 \%$ & $\mathrm{~B} / \mathrm{D}$ & & \\
\hline & & & & $-1.90 \%$ & $E / D$ & & \\
\hline & & & $-10.60 \%$ & $-3.20 \%$ & $\mathrm{~F}, \mathrm{G} / \mathrm{D}$ & & \\
\hline Vienna & \multirow{11}{*}{ Residential } & \multirow{11}{*}{ Continuous } & $\begin{array}{c}\text { Between } \\
10 \% \& 11 \%\end{array}$ & $\begin{array}{l}\text { Between } \\
5 \% \& 6 \%\end{array}$ & step & \multirow{11}{*}{ Listing } & \multirow{11}{*}{$\begin{array}{c}\text { Bio } \\
\text { Intelligence } \\
\text { Service et al. } \\
\text { (2013) }\end{array}$} \\
\hline & & & Between 5\% & & & & \\
\hline Lower Austria & & & $\& 6 \%$ & $4.40 \%$ & step & & \\
\hline Brussels (Flanders) & & & $4.30 \%$ & $3.20 \%$ & step & & \\
\hline Brussels (Capital) & & & $2.90 \%$ & $2.60 \%$ & step & & \\
\hline Brussels (Wallonia) & & & $5.40 \%$ & $1.50 \%$ & step & & \\
\hline Lille & & & $3.20 \%$ & nd & step & & \\
\hline Marseille & & & $4.30 \%$ & nd & step & & \\
\hline Ireland (cities) & & & $1.70 \%$ & $1.40 \%$ & step & & \\
\hline Ireland (not cities) & & & $3.80 \%$ & $1.40 \%$ & step & & \\
\hline Oxford (United Kingdom) & & & $0.40 \%$ & $-4.00 \%$ & step & & \\
\hline \multirow{4}{*}{ United Kingdom } & \multirow{4}{*}{ Residential } & & $5.00 \%$ & & $A, B / D$ & & \\
\hline & & Categorical & $1.80 \%$ & & $C / D$ & Closing & Fuerst et al. \\
\hline & & Categorrcal & $-1.00 \%$ & & $\mathrm{~F}, \mathrm{E} / \mathrm{D}$ & Closing & (2015) \\
\hline & & & $-7.00 \%$ & & G/D & & \\
\hline & $\begin{array}{c}\text { Residential before } \\
\text { 1st July } 2010\end{array}$ & & $2,40 \%$ & & $A, B, C / D, E, F, G$ & & \\
\hline Denmark & & & $10,10 \%$ & & $\mathrm{~A}, \mathrm{~B}, \mathrm{C} / \mathrm{D}, \mathrm{E}, \mathrm{F}, \mathrm{G}$ & & \\
\hline & & & $6,20 \%$ & & $\mathrm{~A}, \mathrm{~B} / \mathrm{D}$ & & \\
\hline & Residential after & Categorical & $5,10 \%$ & & $C / D$ & Closing & Jensen et al. \\
\hline & 1st July 2010 & Categorical & $-5,40 \%$ & & $E / D$ & Closing & 2016 \\
\hline & & & $-12,90 \%$ & & F/D & & \\
\hline & & & $-24,30 \%$ & & G/D & & \\
\hline Italy (Turin) & Residential & Categorical & & $\begin{array}{c}\text { Null } \\
\text { impact }\end{array}$ & & Closing & $\begin{array}{c}\text { Fregonara \& } \\
\text { Rolando } \\
\text { (2016) }\end{array}$ \\
\hline Spain (Madrid, Bilbao, Sev & e, Vitoria \& Málaga) & Categorial & $9,80 \%$ & & $A, B, C / D, E, F, G$ & Opinion & $\begin{array}{l}\text { De Ayala et } \\
\text { al. (2016) }\end{array}$ \\
\hline Spain (Metropolitan Barce & na) & Continuos & $0,85 \%$ & & por clase & & \\
\hline & & & $9,62 \%$ & & $\mathrm{~A} / \mathrm{G}$ & Listing & $\begin{array}{l}\text { Marmolejo } \\
\text { (2016) }\end{array}$ \\
\hline & & & $3,87 \%$ & & $\mathrm{D} / \mathrm{G}$ & & \\
\hline Spain (Metropilitan Alicant & & & $-1,20 \%$ & & por clase & & Marmolejo \\
\hline Spain (Metropolitan Barce & na) & & $1,79 \%$ & & por clase & Listing & \& Chen \\
\hline Spain (Metropolitan Valen & & & $3,30 \%$ & & por clase & & (2019) \\
\hline
\end{tabular}

Source: Own elaboration, based on the cites studies.

\section{Methods and materials}

Stated preferences are used to research whether Spanish households are WTP for efficient homes as assessed under the EPC scheme and their motivations. Contingent valuation (CV) assumes that households are WTP to take advantage of changes that produce an increment in their utility level, or are willing to accept to renounce to such improvement (Mitchell \& Carson, 2013). The CV is integrated into a survey where respondents are informed on the change that potentially can make diverge their utility level (in this case an improvement in the EPC rank). Then, they are asked to state whether they 
are WTP to take advantage of such change (Soguel, 1996). It is assumed that the stated payment is equivalent to the monetary quantity that would return the respondent's utility to the original level. While CV has many advantages over observed preferences methods (e.g. hedonic prices) such as directly inquiring the marginal value of researched attributes, it has been criticized due to the possible existence of a "hypothetical bias" (HB). The HB refers to the possible divergence between stated and actual payments. According to Ehmke et al. (2008), a number of reasons have been argued for the existence of the HB: strategic response, uncertainty about one's value for the assessed good, commitment cost, social desirability bias. However, evidence (Fifer et al., 2014) has shown that HP tends to be smaller when: 1) goods assessed are private, as opposed to public; 2) people are asked to state their WTP instead of their willingness to accept; 3) experiments are realistic (i.e. payment vehicles are familiar and people rely on the feasibility to provide the attributes of the assessed goods), and; 4) individuals are carefully selected so as to ensure convenient experience and appropriate demographics. Following such recommendations in this paper:

- The marginal value of energy efficiency is researched within the residential market which in Spain is largely private.

- WTP is used to learn whether respondents are ready to make an extra payment for efficient homes.

- A realistic payment-vehicle based on an extra-payment in rents/mortgage-installments is used.

- Only adults participating in home decisions participate as respondents, and they were informed that the research was performed within an academic context, so any strategic bias can hardly influence market reactions.

In brief, the CV design/implementation has followed the next steps:

- Typical attributes for multifamily housing have been identified analyzing recent housing completions advertisements to which potential users are exposed to.

- Departing from García-Navarro et al. (2014) and Barboza (2016), the financial and CO2 emissions implications for an improvement "E->A" in the EPC rank has been calculated.

- The aforementioned economic/environmental implications have been computed both in technical (i.e. kWh/sq.m.p.a. and kg) and illustrative units (Euro and traveled km for a family car).

- In order to explore whether the information framework (i.e. the way how respondents are informed on the implications of energy improvements) effects on WTP 3 different versions of the survey were used. Figure 1 explains each of the versions and the structure/motivation of the survey itself.

- After testing the correct understanding of the surveys, by means of a 100 face-to-face pilot test and assessing it by a focus group formed by specialists in property markets and energy efficiency, it was distributed using an online system between spring 2017 and spring 2018.

- Respondents were recruited among different districts and municipalities of Metropolitan Barcelona in order to increase the sociodemographic heterogeneity. Nevertheless, there is an overrepresentation of higher educated respondents, which in turn requires that the results should be carefully treated only as exploratory.

- 1291 surveys were registered from which 841 were completely answered. Surveys lasting less than 5 minutes and more than 20 were eliminated as well as those sharing the same IP/Operating System/web-navigator so as to ensure that the depurated sample is coming from different households.

- Depurated sample consists of 655 surveys, that in relation to the household population represents an error of 2 Euro at 99\% confidence level. 


\section{Survey versions}

Figure 1. Survey versions and structure

\begin{tabular}{|c|c|c|}
\hline EVP1 & & \\
\hline Framework information & Non-information explaining what energy eff iciency is and architectonic attribute & tting on it is provided * \\
\hline Energy consumtion units & kWhr/p.a. of non-renewable primary energy * $\mathrm{CO}_{2}$ emission units & tons/p.a. ${ }^{*}$ \\
\hline EVP2 & & \\
\hline Framework information & Non-information explaining what energy eff iciency is and architectonic attribute & ting on it is provided * \\
\hline Energy consumtion units & $\mathrm{CO}_{2}$ emission units & kms trave lled per year by a fam ily car** \\
\hline EVP3 & & \\
\hline Framework information & Before asking WTP respondents were informed what energy eff iciency is and arc & nic attributes impacting on it \\
\hline Energy consumtion units & Euro/month $\quad \mathrm{CO}_{2}$ emission units & kms trave lled per year by a family car** \\
\hline Surveys' structure & & \\
\hline 1) Introduction & & \\
\hline
\end{tabular}

This section aimed to recall respondents experience concerning energy efficiency in the housing context. Respondents of EVP1 and EVP2 were reminded, using an image, that housings to be let or sold are labelled according to their energy efficiency rank. Next, they were asked to state the attributes that they be lieved are taken into consideration to determ inate such ranks. This information allows to identify how well respondents understand the EPC scheme and its possible repercussion on WTP. Respondents of EVP 3 were clearly informed what energy eff iciency is in housing and, using an image, the architectonic/design attributes impacting on energy consumption and $\mathrm{CO}_{2}$ emissions.

\section{2) WTP assessment}

First, respondents were informed that for a typical "recent completed" apartment (i.e: 3 bedrooms, 80 sq. $\mathrm{m}$. and 2 bathrooms) it is possible to have different EPC ranks. Next, they were informed on the implications in te rms of energy consumption and $\mathrm{CO} 2$ emissions involved in an improvement from rank E to $\mathrm{A}$ (the change assessed). As indicated above, in EVP1 technical units were used, while EVP2 and 3 contained illustrative units. Then, respondents were asked, in the case they were going to le ase or buy such an apartment, whether they were willing to make an extra payment in the monthly rent or mortgage installment. In Spain, taking into consideration housing prices, mortgage rents, credt paybacks and housing yie lds, rents and mortgage payments tend to be similar. Respondents had 3 possible answer options: a) to say they were not willing to pay, b) they wo uld pay more than $30 \mathrm{Euro} / \mathrm{month}$ (i.e. the estim ated savings for the change offered), or c) less than such figure. If option b or $\mathrm{c}$ was selected, respondents were asked to state the specific amount they would pay. The existence of a reference po int (i.e. $30 \mathrm{Euro} / \mathrm{month}$ ) is important in open format CV since it helps to orientate responses. Those responders that said they were not WTP were asked to state the ir reasons in order to identify true-ze ros (i.e. the cases that give null re levance to efficiency im provement) from protest re sponses (i.e. the cases were respondents are re luctant to express the ir WTP due to budget constraints or the overpriced value of housing in Spain.) Finally, responders were asked to express their motivations for making the assessed extra-payment.

\section{3) Sociodemographic and residential profile}

This section includes socio demographic data of respondents. Also the perce ived energetic condtion of the ir present housing was inquired, as well as their priority in carrying out functional, aesthetic or energy retrof its. Such information allows to explore the relation between the stated WTP and the experience of respondents re bted to energy efficiency in their housing context. This section also includes information regarding "sustainable" behavior of respondents in the ir quotidian life, the ir tenure preferences and, finally, the preferred unts to be informed on the economic and environmental impacts of energy efficiency.

Graphic explanation of attributes impacting on energy efficiency in EVP3
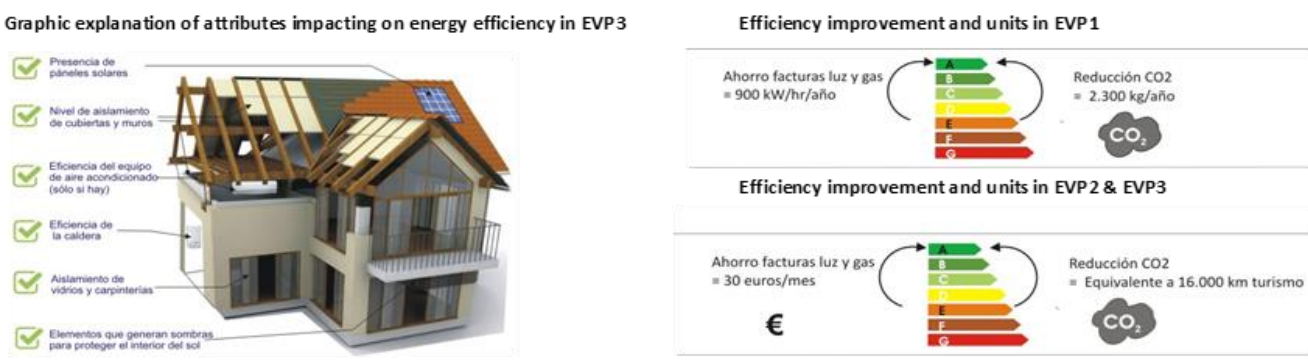

* The same as in the Spanish im plementation of the EPC scheme

** Calculated using information of the Institudo para la Diversificación del Ahorro Energético (Ministry of Industry). In Spain car owners have a clear idea on this

Source: Own elaboration, based on the cites studies.

\section{Results and discussion}

In this section, first the general awareness of respondents about the EPC scheme is analysed, next WTP for efficient homes is discussed, finally, the reasons correlated with such WTP are identified by means of a multiple regression analysis. 


\subsection{Awareness on the EPC scheme}

Figure 2 details the awareness level of EVP1\&2 respondents on the aspects influencing the determination of the EPC ranking. Only $15 \%$ of respondents know the EPC scheme perfectly, so there is a generalized unawareness of the aspects determining the EPC ranks. Using a 0 -to-4 scale $(0=$ null awareness) the average knowledge level is 2.54 , such mean is larger among well-educated, wealthy and young people. This finding suggests that people in a potential risk of fuel poverty are poorly informed on energy efficiency and its implications on family budgets and the environment.

Figure 2. Awareness of the EPC scheme

\begin{tabular}{|c|c|c|c|c|c|c|c|c|}
\hline \multirow{2}{*}{$\begin{array}{l}\text { Awareness of the } \\
\text { EPC scheme }\end{array}$} & \multirow{2}{*}{$\begin{array}{l}\text { All respondents of } \\
\text { EVP1 \& EVP2 }\end{array}$} & \multicolumn{3}{|c|}{ Education level + } & \multicolumn{4}{|c|}{ Age } \\
\hline & & Undergrad & Bachelor & Master or $\mathrm{PhD}$ & 18 to 30 & 31 to 45 & 46 to 65 & Over 65 \\
\hline Null & $1 \%$ & $1 \%$ & $1 \%$ & $0 \%$ & $0 \%$ & $0 \%$ & $2 \%$ & $0 \%$ \\
\hline Low & $8 \%$ & $11 \%$ & $7 \%$ & $8 \%$ & $8 \%$ & $4 \%$ & $8 \%$ & $27 \%$ \\
\hline Medium-low & $44 \%$ & $57 \%$ & $39 \%$ & $39 \%$ & $46 \%$ & $42 \%$ & $41 \%$ & $27 \%$ \\
\hline Medium-high & $32 \%$ & $20 \%$ & $37 \%$ & $35 \%$ & $34 \%$ & $30 \%$ & $29 \%$ & $27 \%$ \\
\hline High & $15 \%$ & $11 \%$ & $16 \%$ & $18 \%$ & $11 \%$ & $24 \%$ & $20 \%$ & $18 \%$ \\
\hline Average $^{*}$ & 2,54 & 2,29 & 2,62 & 2,63 & 2,47 & 2,74 & 2,57 & 2,36 \\
\hline \multirow[t]{3}{*}{ Sig. ANOVA } & & & 0,02 & & & & 0,06 & \\
\hline & & \multicolumn{3}{|c|}{ Family net disposable income a } & & & & \\
\hline & & Medium-low & Medium-high & High & & & & \\
\hline Null & & $1 \%$ & $0 \%$ & $1 \%$ & & & & \\
\hline Low & & $14 \%$ & $8 \%$ & $4 \%$ & & & & \\
\hline Medium-low & & $48 \%$ & $43 \%$ & $41 \%$ & & & & \\
\hline Medium-high & & $28 \%$ & $33 \%$ & $36 \%$ & & & & \\
\hline High & & $9 \%$ & $17 \%$ & $19 \%$ & & & & \\
\hline Average $^{*}$ & & 2,3 & 2,59 & 2,69 & & & & \\
\hline Sig. ANOVA & & & 0,02 & & & & & \\
\hline $\begin{array}{l}\text { Notes: } \\
{ }^{\circ} \text { in order to learn wheth } \\
\text { were taken into conside } \\
\text { construction, water, and } \\
\text { secundary or high scho }\end{array}$ & $\begin{array}{l}\text { er respondents are awar } \\
\text { ation when determining } \\
\mathrm{CO} 2 \text { emissions. The aw } \\
\text { If Medium-low }=\text { less th }\end{array}$ & $\begin{array}{l}\text { e about the EPC sch } \\
\text { the energy performa } \\
\text { arness level is relat } \\
\text { an } 2400 \text { Euro/month }\end{array}$ & $\begin{array}{l}\text { heme, they were as } \\
\text { ince of homes. Ass } \\
\text { ed to the correct a } \\
h, \text { high= more than }\end{array}$ & $\begin{array}{l}\text { asked to state in } \\
\text { sessed factors } \\
\text { answers provide } \\
3600 \text { Euro/mon }\end{array}$ & $\begin{array}{l}1 \& 2 \text { survey } \\
=\text { e ne rgy con } \\
\text { Null }=0 \text {, High= }\end{array}$ & $\begin{array}{l}\text { s the factors } \\
\text { sumption, er } \\
=41+\text { Underg }\end{array}$ & $\begin{array}{l}\text { s they believ } \\
\text { ergy used in } \\
\text { irad= primary }\end{array}$ & e that \\
\hline
\end{tabular}

Source: Own elaboration.

As discussed in section 2, there is evidence indicating a possible misunderstanding of EPC rankings in the case of low-income neighborhoods. Figure 3 shows that in general respondents think that such ranking is a synthetic indicator of the general quality of homes. As a matter of fact, this incorrect belief seems to be slightly correlated with the expected sign with education, age and income, and significantly correlated to the respondent's awareness on the EPC scheme, which in turn, as it has been previously stated, is clearly correlated with sociodemographic indicators. This finding is possibly a consequence of the overnight transposition of the EPBD in Spain and stresses the necessity to improve the diffusion of the aim and meaning of the EPC scheme in order to foster energy-informed property transactions.

On the other hand, the implications of economic and environmental nature require to be easily comprehensible. Figure 4 shows that respondents primarily prefer to be informed using illustrative units instead of technical ones: $74 \%$ of them declared to prefer Euro/month instead of kWh/sq.m./p.a. while $72 \%$ prefer illustrative environmental units (e.g. trees/car emissions) instead of mass units. 
The segmentation by EPC awareness indicates a significant correlation: the higher the understanding of the EPC scheme, the larger the acceptance of technical units. Nevertheless, even in the case of the best-informed household illustrative units are yet preferred.

Figure 3. Misperception of EPC ranking as a global quality

\begin{tabular}{|c|c|c|c|c|c|c|c|c|}
\hline \multirow{2}{*}{$\begin{array}{l}\text { Perception of the EPC } \\
\text { ranking as a synthetic } \\
\text { global quality indicator }\end{array}$} & \multirow{2}{*}{$\begin{array}{c}\text { All } \\
\text { respondents } \\
\text { of EVP1 \& } \\
\text { EVP2 }\end{array}$} & \multicolumn{3}{|c|}{ Education level + } & \multicolumn{4}{|c|}{ Age } \\
\hline & & Undergrad & Bachelor & Master or PhD & 18 to 30 & 31 to 45 & 46 to 65 & Over 65 \\
\hline Yes & $59 \%$ & $61 \%$ & $59 \%$ & $58 \%$ & $62 \%$ & $59 \%$ & $54 \%$ & $44 \%$ \\
\hline No & $41 \%$ & $39 \%$ & $41 \%$ & $42 \%$ & $38 \%$ & $41 \%$ & $46 \%$ & $56 \%$ \\
\hline \multirow[t]{3}{*}{ Sig. Chi-sq ${ }^{\star *}$} & & \multicolumn{3}{|c|}{0,80} & \multicolumn{4}{|c|}{0,169} \\
\hline & & \multicolumn{3}{|c|}{ Family net disposable income $\underline{a}$} & \multicolumn{4}{|c|}{ Awarness of the EPC scheme } \\
\hline & & Medium-low & Medium-high & High & Low & High & & \\
\hline Sí & & $63 \%$ & $58 \%$ & $58 \%$ & $62 \%$ & $54 \%$ & & \\
\hline No & & $37 \%$ & $42 \%$ & $42 \%$ & $38 \%$ & $46 \%$ & & \\
\hline Sig. Chi-sq ${ }^{\star \star}$ & & & & 0,51 & & & & 0,10 \\
\hline
\end{tabular}

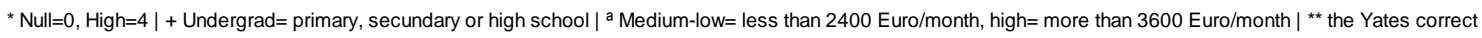

Source: Own elaboration.

The strange language of EPC labels is not a novelty and has been largely recognized to be a barrier in the diffusion of efficient homes both in Spain and Europe (Lainé, 2011). Energy efficiency is a multidimensional and intangible housing attribute whose implications can be largely recognized through experience. Revealing the large proportion of inefficient homes has been the main contribution of EPC in Spain. This issue is exacerbated in cities such as Barcelona where a significant proportion of homes were built in the 1960s in a rapid and low-quality scenario. So, it is expectable to find a correlation between the perceived energy efficiency of the current respondents' home and their willingness to improve such thermic conditions throughout an energy retrofit.

Figure 4. Perceived efficiency of current house and priority to improve thermal conditions

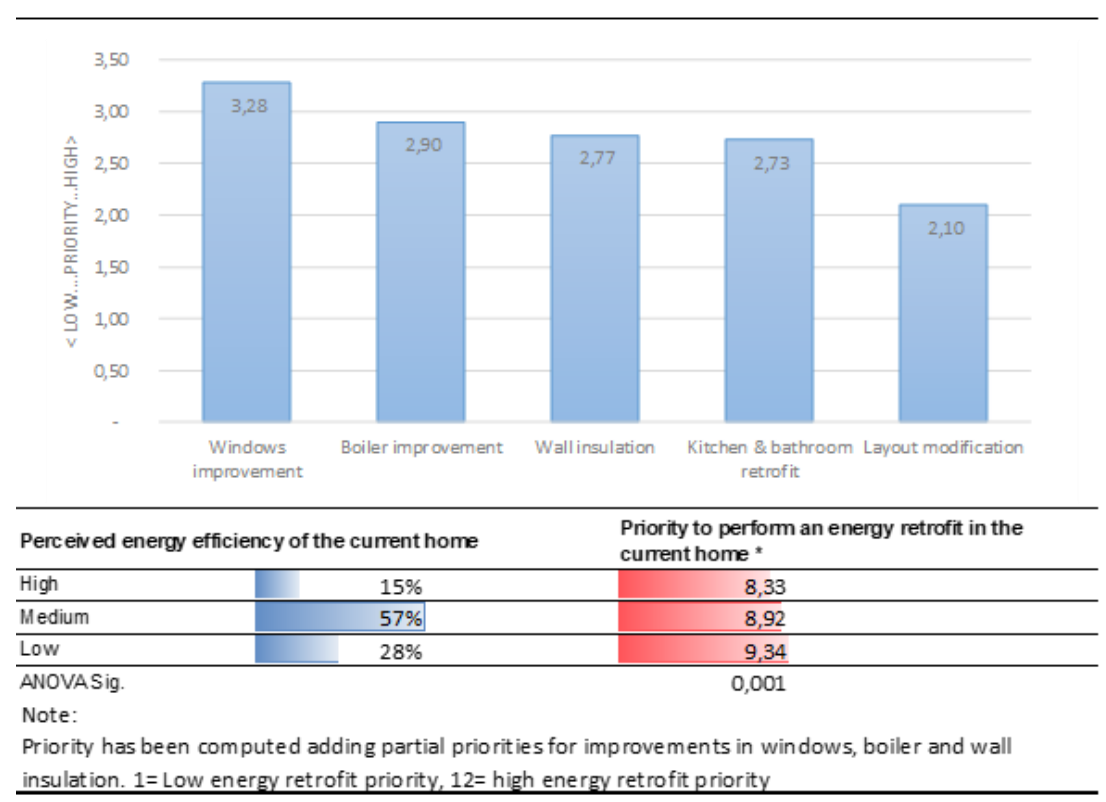

Source: Own elaboration.

ACE, 14 (12) CC BY-ND 3.0 ES | UPC Barcelona, España | How much and why are we willing to pay for energyefficient homes? A stated preferences analysis in Barcelona. DOI: http://dx.doi.org/10.5821/ace.14.42.9215 
Figure 4 shows that only $15 \%$ of respondents believe that they live in an efficient home, while $28 \%$ are in the opposite situation. Furthermore, there is significant variation between such perception and the priority to overcome such a situation performing a retrofit with thermal implications (e.g. insulation or thermal-equipment performance).

From all of the inquired improvements, respondents indicated to have a higher priority to change windows and boilers. Such priority may come from the fact that better-insulated windows exhibit an improved performance also in acoustic terms, while boiler replacement does not imply large disturbances. Interestingly, aesthetic/functional improvements rank low on the "priority ladder" of respondents. This latter finding contrast with the general trend of home retrofitting in Spain where most of the effort, when preparing a home for resale, is invested in "visible" elements.

\subsection{WTP for energy-efficient homes}

92.6\% of valid respondents stated to be ready to make an extra-payment in their rental or mortgageinstallments for the "E->A"-improvement. Interestingly, this rate is quite above normal figures in CV implementations (Riera, 1994), signaling the relevance of energy efficiency in the context of the poor performance of the housing stock and increase of energy prices. 48 respondents are not WTP, 14 cases are "true-zeros" (i.e. energy efficiency is not a relevant aspect for them or the improvement offered is insufficient). The remainder 34 cases were reluctant to pay for a number of reasons commanded by constraints in family budgets or large prices of housing.

After eliminating extreme values (i.e. beyond 2-std-dev) average WTP is 33.43 Euro, the dispersion around such mean (std.dev 20.54 Euro) suggests a heterogeneity among respondents as further explored. Respondents stating a positive WTP were required to declare their motivations to pay. Figure 6 details that such reasons are: future bill savings, reduction of CO2 emissions, as well as comfort and health improvements. On the other hand, aspects such as property revalorization linked to a higher EPC ranking or perceiving the use of efficient homes as an exemplary social action ranked low. While energy and emissions savings are not surprisingly the most argued reasons (since they were included in the offered improvement) it is quite relevant that comfort and health improvement foster positive statements towards home performance. This finding is a clear signal to be used by public policy when recasting the diffusion and communication of the EPC scheme in Spain. On the other hand, it is clear that households do not see energy efficiency as a housing attribute relevant to price formation.

This finding suggests high discount rates: households are ready to pay for the day-to-day benefits on energy efficiency but the present value of such payment is hardly added to property prices. When the sample is stratified by sociodemographic attributes of respondents, some interesting conclusions emerge. According to ANOVA test significant differences are as follows: the higher the education the larger is the WTP motivated by a reduction in CO2 emissions; the same conclusion is valid in terms of health improvement. Also, there is a positive correlation between the respondents' age and WTP aimed at property revalorization. In sum, education and maturity seem to exert an influence over environmental conservation, health and understanding of energy performance as a driver of housing prices. However, the relationship between income and health improvement is inconclusive since younger respondents were more motivated to pay for this reason compared to the elder, while medium-aged ones were the least motivated by this reason. Perhaps, income is proxying for more complex relationships, which in turn require the data to be analyzed using a multivariate approach as done in the next subsection.

ACE, 14 (1.2) CC BY-ND 3.0 ES | UPC Barcelona, España | How much and why are we willing to pay for energy- 
Figure 5. Reasons for WTP by sociodemographic segments

\begin{tabular}{|c|c|c|c|c|c|c|c|c|c|}
\hline & \multicolumn{5}{|c|}{ All respondents } & \multicolumn{4}{|c|}{ Education level } \\
\hline & & & & & & Undergrad & Bachelor & $\begin{array}{c}\text { Master or } \\
\text { PhD }\end{array}$ & $\begin{array}{c}\text { Sig. } \\
\text { ANOVA }\end{array}$ \\
\hline Saving in energy bills & \multicolumn{5}{|c|}{3,63} & 3,7 & 3,6 & 3,6 & 0,34 \\
\hline Contamination reduction & \multicolumn{5}{|c|}{3,47} & 3,4 & 3,5 & 3,6 & 0,04 \\
\hline Is an examplary social action & \multicolumn{5}{|c|}{2,72} & 2,7 & 2,7 & 2,7 & 0,99 \\
\hline Housing price increase & \multicolumn{5}{|c|}{2,79} & 2,9 & 2,7 & 2,8 & 0,07 \\
\hline Health improvement & \multicolumn{5}{|c|}{3,23} & 3,3 & 3,2 & 3,4 & 0,03 \\
\hline Comfort imrpovement & 3,29 & & & & & 3,4 & 3,3 & 3,2 & 0,20 \\
\hline \multirow[t]{2}{*}{$\mathrm{N}=607$} & \multicolumn{5}{|c|}{ Age } & \multicolumn{4}{|c|}{ Net family income } \\
\hline & 18 to 3 & 31 to 45 & 46 to 65 & $>65$ & $\begin{array}{c}\text { Sig. } \\
\text { ANOVA }\end{array}$ & $\begin{array}{l}\text { Medium- } \\
\text { low }\end{array}$ & $\begin{array}{l}\text { M edium- } \\
\text { high }\end{array}$ & High & $\begin{array}{l}\text { Sig. } \\
\text { ANOVA }\end{array}$ \\
\hline Saving in energy bills & 3,6 & 3,6 & 3,7 & 3,5 & 0,32 & 3,7 & 3,6 & 3,6 & 0,56 \\
\hline Contamination reduction & 3,5 & 3,4 & 3,5 & 3,2 & 0,36 & 3,5 & 3,4 & 3,5 & 0,61 \\
\hline Is an examplary social action & 2,7 & 2,7 & 2,8 & 2,4 & 0,42 & 2,8 & 2,7 & 2,7 & 0,73 \\
\hline Housing price increase & 2,7 & 2,7 & 3,0 & 2,9 & 0,00 & 2,8 & 2,8 & 2,8 & 0,61 \\
\hline Health improvement & 3,2 & 3,3 & 3,3 & 3,2 & 0,11 & 3,3 & 3,1 & 3,2 & 0,09 \\
\hline Comfort imrpovement & 3,2 & 3,3 & 3,4 & 3,4 & 0,12 & 3,3 & 3,2 & 3,3 & 0,53 \\
\hline
\end{tabular}

Source: Own elaboration.

\subsection{Explanatory variables behind WTP}

In order to identify the factors correlated with the stated WTP, a multiple regression analysis has been done. In this approach, the possible explanatory variables are: respondent's sociodemographic characteristics, experience coming from present housing, respondents' sustainable behavior, as well as the way how respondents were informed on energy performance implications (Table 1). Figure 7 depicts the significant univariate correlations between the log of WTP (this transformation is used in the further regression model) and the independent attributes organized in conceptual dimensions. In the "sustainable behavior" dimension there is a positive correlation between WTP and waste segregation, as well as energy conservation attitudes (e.g. turn the light off when not in use). The negative correlation with the use of public transport may be masking the income level, since the larger the income, the less the use of this transport mode. In the dimension of "retrofit priority" in the current home the inverse correlation with functional/aesthetic retrofit is largely coherent with the results discussed in Figure 6.

The results of the "motivation for WTP" dimension depict interesting findings. The largest correlations run on health improvement and environmental conservation. Meanwhile, reasons such as energy savings or property revalorization are little or not correlated with WTP. In the respondents' "sociodemographic attributes" dimension income is the most correlated variable, as a matter of fact, this association with WTP is the most important from all of the correlations. The negative correlation between the sex variable and WTP suggests that women are more prudent when bidding for energy efficiency. This finding is in line with evidence stressing that women make deeper investment assessments compared to men (Hullgren \& Söderberg, 2013). Especially when a larger WTP for buying an efficient home implies risks, such as not recovering this extra-investment by means of energy bill cuts. The awareness of the EPC scheme appears as positively correlated with WTP, while the misunderstanding of EPC rankings as a global quality indicator exhibits a negative correlation. Both of these findings are of paramount interest since they imply that the correct understanding of the scheme can boost the demand for efficient properties in line with EPBD's expectations. Finally, unemployed participants expressed a lower WTP, highlighting the consistency of the answers. 
Figure 6. Correlations between WTP and potential explanatory variables

\begin{tabular}{|c|c|c|c|c|c|c|c|c|}
\hline Conceptua dimension & Explanatory variable & $\begin{array}{l}\text { Spearman } \\
\text { correlation } \\
\text { vs } \ln (\text { WTP) }\end{array}$ & Sig. & Min. & Max. & Average & Std. Dev, & Meaning or units \\
\hline \multirow{3}{*}{ Sustainable behaviours } & Waste segregation & 0.08 & 0.05 & 1 & 4 & 3.41 & 0.93 & $1=$ never, $4=$ always \\
\hline & Use of public transport when possible & 0.07 & 0.10 & 1 & 4 & 3.15 & 0.99 & $1=$ never, $4=$ always \\
\hline & Turn light devices/light & 0.08 & 0.06 & 1 & 4 & 3.67 & 0.57 & $1=$ never, $4=$ always \\
\hline \multirow{5}{*}{$\begin{array}{l}\text { Retrofit priority in the } \\
\text { present home }\end{array}$} & Kitchen \& bathroom retrofit & 0.10 & 0.02 & 1 & 4 & 2.74 & 0.97 & 1=low, 4=high \\
\hline & Layout modification & 0.02 & 0.59 & 1 & 4 & 2.08 & 0.94 & 1=low, 4=high \\
\hline & Wall insulation & 0.00 & 0.92 & 1 & 4 & 2.78 & 1.00 & 1=low, 4=high \\
\hline & Windows improvement & 0.03 & 0.50 & 1 & 4 & 3.29 & 0.93 & 1=low, 4=high \\
\hline & Boiler improvement & 0.04 & 0.28 & 1 & 4 & 2.91 & 0.97 & 1=low, 4=high \\
\hline \multirow{6}{*}{ Motivation for WTP } & Saving in energy bills & 0.07 & 0.09 & 1 & 4 & 3.64 & 0.59 & 1=disagreed | 4= strongly agreed \\
\hline & Contamination reduction & 0.14 & 0.00 & 1 & 4 & 3.48 & 0.68 & 1=disagreed | 4= strongly agreed \\
\hline & Is an examplary social action & 0.11 & 0.01 & 1 & 4 & 2.73 & 0.91 & 1=disagreed | 4= strongly agreed \\
\hline & Housing price increase & 0.03 & 0.46 & 1 & 4 & 2.79 & 0.86 & 1=disagreed | 4= strongly agreed \\
\hline & Health improvement & 0.15 & 0.00 & 1 & 4 & 3.23 & 0.74 & 1=disagreed | 4= strongly agreed \\
\hline & Comfort imrpovement & 0.11 & 0.01 & 1 & 4 & 3.29 & 0.76 & $1=$ disagreed $\mid 4=$ strongly agreed \\
\hline \multirow{14}{*}{$\begin{array}{l}\text { Sociodemographic } \\
\text { attributes }\end{array}$} & $\begin{array}{l}\text { Perceived energy performance of the } \\
\text { current home }\end{array}$ & 0.07 & 0.11 & 1 & 3 & 2.12 & 0.64 & 1=low, 4=high \\
\hline & Education & 0.02 & 0.62 & 1 & 7 & 5.41 & 1.26 & $1=$ primary, $7=$ master or $\mathrm{PhD}$ \\
\hline & Age & 0.10 & 0.02 & 24 & 70 & 35.00 & 14.13 & years \\
\hline & Net family disposable income & 0.17 & 0.00 & 600 & 4800 & 2,599 & 1,250 & Euro/month \\
\hline & EPC awarness & 0.09 & 0.03 & 0 & 4 & 1.76 & 1.38 & $0=$ null, $4=$ high \\
\hline & EVP1's respondents & 0.08 & 0.06 & 0 & 1 & 0.35 & 0.48 & $(\%)$ \\
\hline & EVP2's respondents & 0.00 & 0.95 & 0 & 1 & 0.35 & 0.48 & (\%) \\
\hline & EVP3's respondents & 0.08 & 0.06 & 0 & 1 & 0.31 & 0.46 & (\%) \\
\hline & Energy retrofit* & 0.02 & 0.61 & 3 & 12 & 8.98 & 2.22 & $3=$ null, $12=$ high \\
\hline & Environment conservation** & 0.04 & 0.37 & 3 & 12 & 10.22 & 1.64 & $3=$ null, $12=$ high \\
\hline & Woman & 0.13 & 0.00 & 0 & 1 & 0.48 & 0.50 & $(\%)$ \\
\hline & Prefer to buy instead of lease & 0.01 & 0.85 & 1 & 2 & 1.59 & 0.49 & $1=$ prefers to buy \\
\hline & $\begin{array}{l}\text { Misunderstading of EPC ranking as a } \\
\text { global quality indicator }\end{array}$ & 0.10 & 0.01 & 1 & 2 & 1.40 & 0.49 & $1=$ misunderstanding \\
\hline & $\begin{array}{l}\text { Will not change behaviour towards } \\
\text { energy conservation }\end{array}$ & 0.07 & 0.10 & 0 & 1 & 0.55 & 0.50 & (\%) \\
\hline \multirow{4}{*}{ Ocupation status } & Student & 0.06 & 0.16 & 0 & 1 & 0.39 & 0.49 & (\%) \\
\hline & Unemployed & 0.03 & 0.52 & 0 & 1 & 0.02 & 0.15 & (\%) \\
\hline & Employed & 0.07 & 0.09 & 0 & 1 & 0.56 & 0.50 & $(\%)$ \\
\hline & Retired/other & 0.01 & 0.78 & 0 & 1 & 0.04 & 0.19 & (\%) \\
\hline \multicolumn{9}{|c|}{$\begin{array}{l}\text { Notes } \\
\text { * This variable has been computed departing from respondents willing to improve the windows, boiler and wall insulation } \\
\text { ** This variable has been computed departing from "sustainable" behaviours declared by respondents } \\
\text { Variables whose correlation with In(WTP) failed to be statistical significant at } 90 \% \text { of confidence level are shown in grey } \\
\mathrm{N}=600 \text {, after eliminating outliers }\end{array}$} \\
\hline
\end{tabular}

Source: Own elaboration.

Figure 7 contains the results of the set of models implemented to identify the attributes correlated with WTP, the log of this dependent variable allows to attain the standard requirements of the ordinary-least-squares procedure. Also, in this transformation the coefficients are expressed as semielasticities allowing to compare them with the result of other studies. The MOD 1G has been specified using all the cases in the depurated sample. According to the beta coefficient (built on standardized scales) income is the main explanatory variable: 1000 Euro/month of income increase is translated into $8 \%$ of increment in WTP. The next variable is the health perception, for each of the steps in the Likert ladder of such variable, WTP increases also $8 \%$. The sex of respondents is the third explanatory variable: so, men are WTP 12\% more than women. The incorrect understanding of EPC ranking as a global quality indicator appears with the negative sign, as well as the fact that the respondent is a tenant or live in a relative's home. This latter finding has, at least, two interpretations. On the one hand, it is possible that energy efficiency is irrelevant when energy bills are paid by others (e.g. parents). On the other hand, it seems that energy efficiency is irrelevant in the case of "temporal housing". It is important to recall that in Spain, according to data from the National Institute of Statistics, $72 \%$ of households are owner-occupiers, so lease tenure is seen as a transition towards ownership. As a matter of fact, hedonic analysis reviewed in table 1, shows a smaller marginal price for EPC rankings in the leasing market in relation to the selling one. 
Paradoxically, respondents of the EVP3 survey (which were informed using illustrative units and were explained what energy efficiency is), appear as negatively correlated with WTP (i.e. they are WTP less than EVP1 respondents). This issue may be possibly explained by 2 divergent situations:

- Firstly, respondents of EVP1 (whose WTP is larger than that of respondents of EVP3 according to regression coefficients), although they were not informed about what energy efficiency is, and which architectonic attributes effect on it, were required to perform a cognitive effort when inquired on the aspects they believe are taken into consideration when determining the EPC ranking of a home. It is possible that such an "active" effort helped respondents to give more importance to energy efficiency when they were required to state their WTP.

- Secondly, respondents of EVP1 were informed that upgrading the offered home from "E->A" ranking implies an energy-saving equivalent to $900 \mathrm{kWh} /$ p.a. (i.e. using the same format that in actual EPC labels); meanwhile, EVP3 respondents were informed that such saving was 30 Euro/month. The difference between such (equivalent) figures may have influenced the stated WTP.

The implications of this finding for public policy are relevant since the diffusion of energy efficiency should extend beyond the informative sphere and incite a more reflexive attitude. Also, the units used to express the economic implications are not trivial since they should help to identify the impact of energy efficiency on family budgets.

Figure 7. WTP explicative models

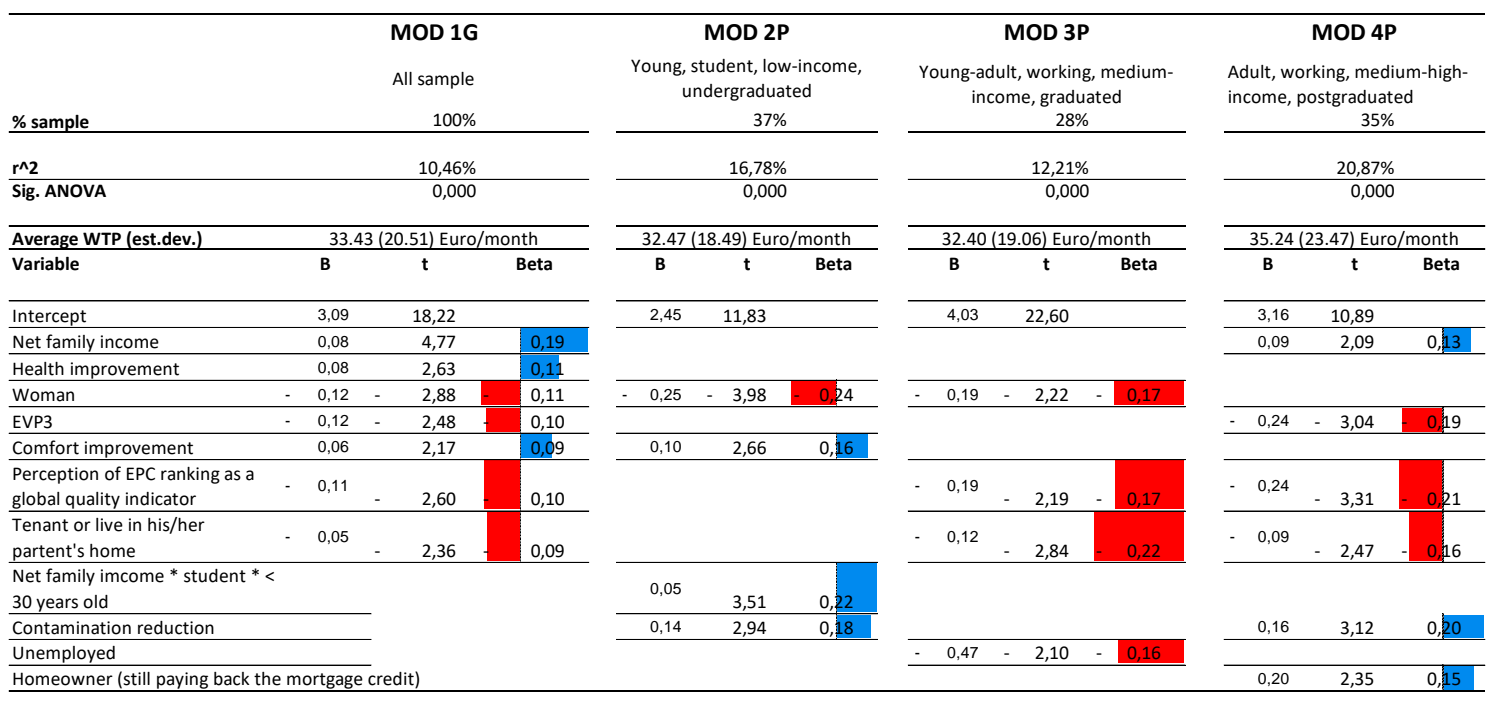

Notes: dependent variable $\ln ($ WTP); the estimation has followed the stepwise procedure

Source: Own elaboration.

MOD $1 G$ has a limited fit (it only explains 10\% of WTP's variance); such poor performance may be masking divergent sensibilities related to energy efficiency. In order to test such divergence, the sample has been split into 3 segments departing a factor analysis (aimed to eliminate redundant information) followed by a clustering procedure built on principal components coming from the first analysis. Segmentation variables are: age, occupation status, income, and education. As a result, respondents have been grouped in more homogeneous sub-groups as follows:

- Young undergraduate people, studying, whose income, in general, ranges in the lower tier.

- Young adults, graduated, working and holding medium-income.

- Adults, postgraduate, working and holding medium-high-income.

ACE, 14 (1.2) CC BY-ND 3.0 ES | UPC Barcelona, España | How much and why are we willing to pay for energyefficient homes? A stated preferences analysis in Barcelona. DOI: http://dx.doi.org/10.5821/ace.14.42.9215 
As detailed in table 9, the first 2 clusters exhibit a similar mean WTP, while the third exhibits a larger one, with a higher standard deviation. The fit indicator (R2) is larger in all of the partial models (i.e. MOD 2P-to-4P) which is in line with the hypothesis of different sensibilities. The results of such partial models portray interesting insights:

- In MOD 2P women are WTP 25\% less than the male of that sub-group; however, wealthy respondents of such sub-group even when they are students and under 30-year old are WTP 5\% more for efficient homes for each 1000 Euro their net family income increases. In sum, young respondents whose education is in progress, seem to have developed an environmental concern that is transformed into a larger WTP when family economic conditions are favorable, although such a bid is moderated in the case of women, especially in the case of young women.

- MOD 3P has been calibrated with the responses largely coming from young adults, employed, mid-income and medium university qualifications. In such a model the main explanatory variable is the fact that respondents are tenants or cohabitate in their parent's homes. This finding is quite interesting since it stresses the impact of tenure regime over the economic implications of energy efficiency. Also, young adults that have failed to emancipate are less prepared to pay for such attribute, since they are not fully aware of the family budget impact of energy bills or simply because they are not in financial conditions to establish an independent household. This latter conjecture is in line with the negative correlation between WTP and unemployment, which in turn is a huge issue for young people in Spain.

Finally, MOD 4P, specified with information coming from working adults holding postgraduate studies and medium-high-income, points that the main explanatory variable of WTP is, with a negative sign, the incorrect perception of EPC ranking as a global indicator of a home's quality. In short, respondents that incorrectly perceive the role of such ranking are WTP 24\% less than people that correctly understand the EPC scheme. The remainder of independent variables does exhibit the expected sign: positive both for income and owners paying back their mortgage. This latter finding suggests that people that "recently" bought a home are more sensitive to positively value energy efficiency, perhaps due to a larger knowledge of the energy attributes of the housing stock.

\section{Conclusions}

While evidence of the impact of EPC ranks on housing prices is somewhat inconclusive, none of the previous studies have explored the reasons that people have to make an extra-payment for efficient homes. This paper explores, 1) the awareness of households regarding the EPC scheme, 2) the impact of such awareness over the willingness to pay (WTP) for efficient homes as well as the impact coming from other variables such as sociodemographic attributes, "sustainable" behaviours and the way in how people are informed on what is energy efficiency in home, as well as its economic and environmental implications. To address these issues, a survey, containing a contingent valuation, has been implemented in Metropolitan Barcelona since this area is representative of large cities in Spain. Finally, using an econometric approach, the attributes correlated with WTP have been identified. The main findings are summarized as follows:

- There is a generalized unawareness of the EPC scheme, especially in the case of the population in a potential risk of fuel poverty. So, less educated, low-income and aging people exhibit a poor knowledge of the aim of this policy tool. Furthermore, there is a large confusion regarding the role of EPC rankings: most of our respondents think they are a synthetic indicator of global housing quality. Such findings are not surprising due to the Spanish overnight transposition of the Energy Performance of Buildings Directive (EPBD): between the date of publication of the RD 235/2013 and the date when EPC labels became mandatory there were only 47 days, at the time that the diffusion was extremely limited due public budget constraints.

- The unawareness and misunderstanding of the EPC scheme is not a trivial issue since they appear inversely correlated with WTP. Respondents that have a correct perception of EPC rankings are

ACE, 14 (1.2) CC BY-ND 3.0 ES | UPC Barcelona, España | How much and why are we willing to pay for energy- 
more likely to make an extra-payment for efficient homes. So, the wrong policy around the EPC diffusion in Spain has a direct impact on the promotion of efficient buildings as expected by the EPBD.

- However, according to our results, it seems that environmental concern creation requires a strategy going beyond information provision. In our experiments, respondents that were forced to think which elements are taken into consideration when determining energy efficiency in homes, stated a larger WTP, in relation to respondents that were simply informed on what energy efficiency is and the architectonical attributes impacting on it.

- On the other hand, while energy savings are the most important reason to be ready to make an extra-payment for efficient homes, they are not correlated with the monetary figure that respondents said to be willing to pay. The factors explaining WTP variance are: income, and interestingly the belief that efficient homes provide improved comfort and health. Also, women exhibit a more prudent position when declaring their WTP. Furthermore, the tenancy regime appears inversely correlated with WTP, which implies that tenants do pay less attention to the home's performance due to its temporal nature in a country of homeowners. The same is true for respondents living with their parents.

- The segmentation of the sample undercovers divergent sensibilities/perceptions towards energy performance. Young respondents, even when their education is in progress, are WTP more if the family income is favourable. Also, they exhibit a larger concern for environmental conservation. Conversely, young medium-income workers holding a medium university degree, state to be ready to pay less when they incorrectly understand the aim of the EPC scheme. Finally, adults with larger income and postgraduate education also exhibit a larger concern on environmental protection and those still paying back their homes are willing to make a larger extra-payment.

These findings are broadly in line with past research on the reasons to adopt energy-efficient devices or to carry out energy retrofits. Among others, this research body has found that behind observed or stated preferences are in environmental aspects (e.g. climate); personal factors (e.g. income, environmental concern); economic (e.g. energy prices); housing attributes (e.g. size, typology and age) and policy-related (e.g. tax rebates and subsidies (Kwan, 2012; Davidson et al., 2014; Morton et al., 2018).

The findings of this paper imply important challenges for the communication of the EPC policy in Spain, not only because society is not monolithic, having divergent motivations when bidding for efficient housing, but also because superficial information seems to be inefficient in creating awareness on the implication of the energy performance of buildings. In such a line, Marmolejo et al. (2020a) after surveying real estate agents, do propose some policies aligned with information campaigns and financial support, while Marmolejo et al. (2020b) after in-depth interviewing the main agents in residential production arrive at compatible conclusions, that include the enrolment of $R+D$ and the inclusion of energy-efficiency co-benefits in the "green-marketing" of energy efficiency.

\section{Acknowledgments}

This paper has been produced within the framework of EnerVALOR project (MINECO FEDER BIA201563606-R).

\section{Authorship}

The authors have worked together in the design of the methodology, analysis of the data and results, in addition to the writing of the article.

Conflict of interests: The authors declare no conflict of interest.

ACE, 14 (1.2) CC BY-ND 3.0 ES | UPC Barcelona, España | How much and why are we willing to pay for energyefficient homes? A stated preferences analysis in Barcelona. DOI: http://dx.doi.org/10.5821/ace.14.42.9215 


\section{Bibliography}

Barboza Baamode, M. E. (2016). Evaluación de costes y beneficios de una mayor cuantificación energética en el mercado residencial de nueva planta en Barcelona. Master Thesis, Universitat Politècnica de Catalunya, Barcelona. Retrieved from http://hdl.handle.net/2117/84402

Bio Intelligence Service; Lyons, R.; IEEP. (2013). Energy Performance Certificates in Buildings and Their Impact on Transaction Prices and Rents in Selected EU Countries, Final Report Prepared for European Commission (DG Energy), Paris, France, Retrieved from: https://ec.europa.eu/energy/sites/ ener/files/documents/20130619-energy performance certificates in buildings.pdf

Davidson, C.; Drury, E.; Lopez, A.; Elmore, R. \& Margolis, R. (2014). Modeling photovoltaic diffusion: an analysis of geospatial datasets. Environmental Research Letters, 9(7), 074009. DOI: http://dx.doi.org/10.1088/1748-9326/9/7/074009

Ehmke, M. D.; Lusk, J. L. \& List, J. A. (2008). Is hypothetical bias a universal phenomenon? A multinational investigation. Land economics, 84(3), 489-500. DOI: http://doi.org/10.3368/le.84.3.489

Fifer, S.; Rose, J. \& Greaves, S. (2014). Hypothetical bias in Stated Choice Experiments: is it a problem? And if so, how do we deal with it? Transportation research part A: policy and practice, 61, 164-177. DOI: https://doi.org/10.1016/j.tra.2013.12.010

Fregonara, E.; Rolando, D. \& Semeraro, P. (2017). Energy Performance Certificates in The Turin Real Estate Market. Journal of European Real Estate Research, 10(2), 149-169. doi: https://doi.org/10.1108/JERER-05-2016-0022

García Navarro, J.; González Díaz, M. J. \& Valdivieso, M. (2014). «Estudio Precost\&e»: evaluación de los costes constructivos y consumos energéticos derivados de la calificación energética en un edificio de viviendas situado en Madrid. Informes de la construcción, 66(535), 1-10. DOI: https://doi.org/10.3989/ic.13.052

Hullgren, M. \& Söderberg, I. L. (2013). The relationship between consumer characteristics and mortgage preferences: a case study from Sweden. International Journal of Housing Markets and Analysis, 6(2), 209-230. DOI: https://doi.org/10.1108/IJHMA-01-2012-0004

Kwan, C. L. (2012). Influence of local environmental, social, economic and political variables on the spatial distribution of residential solar PV arrays across the United States. Energy Policy, 47, 332-344. DOI: http://dx.doi.org/10.1016/j.enpol.2012.04.074

Lainé, L. (2011). Room for Improvement. The Impact of EPCs on Consumer Decision-Making. London, United Kingdom: Consumer Focus.

Marmolejo-Duarte, C. (2016). La Incidencia de La Calificación Energética sobre Los Valores Residenciales: Un Análisis para El Mercado Plurifamiliar en Barcelona. Informes de la Construcción, 68(543), 156. DOI: https://doi.org/10.3989/ic.16.053

Marmolejo-Duarte, C. \& Chen, A. (2019). The Uneven Price Impact of Energy Efficiency Ratings on Housing Segments and Implications for Public Policy and Private Markets. Sustainability, 11(2), 372. DOI: https://doi.org/10.3390/su11020372 
Marmolejo-Duarte, C. \& Chen, A. (2019a). The evolution of energy efficiency impact on housing prices. An analysis for metropolitan Barcelona. Revista de la Construcción, 18(1), 156-166. DOI: https://doi.org/10.7764/RDLC.18.1.156

Marmolejo-Duarte, C.; Chen, A. \& Bravi, M. (2020). Spatial implication of EPC ranking over residential prices. In Mondini, G. et al. (Ed.) Values and functions for future cities (pp. 51-71). Cham, Switzerland: Springer Nature.

Marmolejo-Duarte, C.; Spairani, S.; Del Moral-Ávila, C. \& Delgado, L. (2020a). The Relevance of EPC Labels in the Spanish Residential Market: The Perspective of Real Estate Agents. Buildings, 10(2), 27. DOI: https://doi.org/10.3390/buildings10020027

Marmolejo Duarte, C.; Spairani, S. \& García-Hooghuis, A. (2020). Overview of the Energy Performance Certificates in Spain. The perspective of the main actors of the real estate housing industry. Ciudad $y$ Territorio: Estudios Territoriles, in press.

Mitchell, R. \& Carson, R. (2013). Using Surveys to Value Public Goods: The Contingent Valuation Method. New York, USA: Taylor \& Francis. DOI: http://doi.org/10.4324/9781315060569

Morton, C.; Wilson, C. \& Anable, J. (2018). The diffusion of domestic energy efficiency policies: A spatial perspective. Energy Policy, 114, 77-88. DOI: https://doi.org/10.1016/j.enpol.2017.11.057

Murphy, L. (2014). The Influence of the Energy Performance Certificate: The Dutch Case. Energy Policy, 67, 664-672. DOI: https://doi.org/10.1016/j.enpol.2013.11.054

Olaussen, J. O.; Oust, A. \& Solstad, J. T. (2017). Energy Performance Certificates-Informing the Informed or The Indifferent? Energy Policy, 111, 246-254. DOI: https://doi.org/10.1016/j.enpol.2017.09.029

Olaussen, J. O.; Oust, A. \& Solstad, J. T. (2019). Energy Performance Certificates - The Role of the Energy Price. Energies, 12(18), 3563. DOI: http://doi.org/10.3390/en12183563

Parkinson, A.; De Jong, R.; Cooke, A. \& Guthrie, P. (2013). Energy Performance Certification as a Signal of Workplace Quality. Energy policy, 62, 1493-1505. DOI: https://doi.org/10.1016/j.enpol.2013.07.043

Pascuas, R. P.; Paoletti, G. \& Lollini, R. (2017). Impact and Reliability of EPCs in The Real Estate Market. Energy Procedia, 140, 102-114. DOI: https://doi.org/10.1016/j.egypro.2017.11.127

Riera, P. (1994). Manual de Valoración Contingente, Madrid; Ministerio de Economía y Hacienda. Instituto de Estudios Fiscales. Available online: http://pagines.uab.cat/pere.riera/sites/pagines.uab.cat.pere.riera/files/manualcvm2.pdf (accessed on 9 April 2019).

Soguel, N. (1996). Contingent valuation of traffic noise reduction bebefits. Revue Suisse d'Economie Politique et de Statistique, 132, 109-123. Retrieved from https://s3.amazonaws.com/academia.edu.do cuments/46496194/1996-I-5.pdf?AWSAccessKeyld=AKIAIWOWYYGZ2Y53UL3A\&Expires=1554832720\& Signature=vRdOCOWyY\%2FdIhIKK8pMrryi\%2BBWA\%3D\&response-content-disposition=inline\%3B\%20 filename\%3DContingent Valuation of Traffic Noise Re.pdf 